\title{
Book Review: Implementing Systems Engineering Techniques into Health Care: An Investigation into Using Problem-Based Learning in Medical Schools to Teach Systems Engineering
}

Mark A. Best

Lake Erie College of Osteopathic Medicine-Bradenton

IJPBL is Published in Open Access Format through the Generous Support of the Teaching Academy at Purdue University, the School of Education at Indiana University, and the Jeannine Rainbolt College of Education at the University of Oklahoma.

\section{Recommended Citation}

Best, M. A. (2010). Book Review: Implementing Systems Engineering Techniques into Health Care: An Investigation into Using Problem-Based Learning in Medical Schools to Teach Systems Engineering. Interdisciplinary Journal of Problem-Based Learning, 4(1).

Available at: https://doi.org/10.7771/1541-5015.1160

This document has been made available through Purdue e-Pubs, a service of the Purdue University Libraries. Please contact epubs@purdue.edu for additional information.

This is an Open Access journal. This means that it uses a funding model that does not charge readers or their institutions for access. Readers may freely read, download, copy, distribute, print, search, or link to the full texts of articles. This journal is covered under the CC BY-NC-ND license. 


\title{
Book Review
}

\section{Implementing Systems Engineering Techniques into Health Care: An Investigation into Using Problem Based Learning in Medical Schools to Teach Systems Engineering}

\begin{abstract}
Mark A. Best
Fitzler, J. (2008) Implementing Systems Engineering Techniques into Health Care: An Investigation into Using Problem Based Learning in Medical Schools to Teach Systems Engineering. Saarbrücken: VDM Verlag. 64 pp. ISBN 978-3-8364-3782-0. \$64.00 (pbk).

Keywords: book review

There is variation in quality of health care systems. Pockets of excellence exist, but there is plenty of room for improvement. As the sixteenth-century astronomer Johannes Kepler stated, "errors show us the way to the truth" (qtd. in Koyre, 1973, p. 110). We can learn from errors. If we spend the effort to learn from errors, and use the science of quality improvement to make changes in the process and system, then health care quality can be improved. The traditional approach to quality focuses on the patient or population. That is great, but the focus needs to be on the patient and population and the health care system simultaneously. Health care quality can be improved using a systems engineering approach. This book looks at problem-based learning (PBL) as a vehicle for teaching systems engineering techniques to medical students.

The science of quality improvement is young. Though physicians have the knowledge of medicine and patient care, the majority does not have the "profound knowledge," as Deming (2000, p. xi) called it, necessary for healthcare system improvement. Two of the core competencies for medical students and physicians-in-training (residents) are "systems-based practice" and "practice-based learning and improvement."This book helps physicians understand what these competencies mean. This book is for medical educators, as well as for others in health care who want to implement change. While improvement requires change, all change does not lead to improvement. Thus, understanding the healthcare system is necessary for improving patient safety and quality, and decreasing costs due to waste.
\end{abstract}

The Interdisciplinary Journal of Problem-based Learning • volume 4, no. 1 (Spring 2010) 
It is imperative that physicians learn about the science of quality improvement early in their careers, as they exhibit less resistance to change. To quote Fitzler in this book:

Teaching medical students has another advantage. They can be taught without previous bias or resentment. If they are presented systems concepts in medical school, they are likely to regard the subject matter as important. This is in contrast to trying to teach a well-established physician a new way to look at heath care processes and indeed health care as a whole. The experienced physician is less likely than medical students to assign these skills as important. Therefore, teaching medical school students these skills will hopefully lead to their use in the medical community in the near future. ... Many of the challenges in the health care industry are very complex and can be understood only by looking at them in a systems perspective. (p. 13)

This book is divided into five chapters, an appendix (with four parts), and references. As the title suggests, the book discusses an example of using PBL as the platform for teaching medical students concepts of systems engineering. Chapter 1 is an introduction, chapter 2 is the literature review, chapter 3 discusses the project plan, chapter 4, results, and chapter 5 , conclusions.

This book describes a healthcare system as consisting of three parts: 1) information and control, 2) human and organization, and 3) facilities. As the author points out, a key step in the problem solving cycle is "solving the problem so it does not happen again. This is the step that is currently missing in many health care environments" (pp. 6-7). By fixing the system, the matter is addressed for the long term, in a proactive sense. Otherwise, the solution is just a reaction to the problem resulting in a short-term outcome.

The PBL curriculum uses educational objectives on which the students will be assessed. PBL facilitators (or tutors) play a major role in the PBL process. Some conclusions were drawn regarding $P B L$ as a method for teaching systems engineering. PBL tutors who allow students to lightly skim over systems engineering concepts are communicating that this lacks importance. Also repetition of concepts by including them in multiple PBL-cases reinforces their importance. Thus there are critical control points in the PBL process and in the PBL curriculum design.

Overall, the book gives an introduction to some basic systems engineering terms and concepts. What is also communicated is the importance of linking design with process and process with outcomes. The micro-system of PBL requires ownership and communication of curriculum by educators. As students try to link effort to outcomes, they will study what they deem important to assessment and to practice. Thus the importance of communication and system design is paramount to improving outcomes. This book gives a good description of introductory health care system concepts. 


\section{References}

Deming, W. E. (2000). The new economics for industry, government, education ( $2^{\text {nd }}$ ed.). Cambridge: MIT Press

Koyre, A. (1973). The astronomical revolution. New York: Cornell University Press.

Mark A. Best is Associate Professor of Pathology and Director of the Spirituality, Medicine, and Ethics course at Lake Erie College of Osteopathic Medicine-Bradenton. He is chair of the PBL-case improvement committee, and is an expert in the physician core competencies of systems-based practice and practice-based learning and improvement.

Correspondence concerning this article should be addressed to Mark A. Best, LECOM Bradenton, 5000 Lakewood Ranch Boulevard, Bradenton, FL 34211-4909.

- volume 4, no. 1 (Spring 2010) 